\title{
Understanding change in professional road cycling
}

Stephen Morrow and Catharine Idle

Department of Sports Studies

The University of Stirling

Stirling

Scotland, UK.

Correspondence to: $\underline{\text { s.h.morrow@stir.ac.uk }}$

Tel: 00441786466495

Fax: 00441786466919

We are grateful to the British Academy for funding this research. We would also like to thank participants at the Workshop on Theoretical Approaches to Change in Sport Organisations at EASM in Turin in September 2007 and to the anonymous referees for their comments on earlier drafts of this paper. 


\title{
Understanding change in professional road cycling
}

\author{
Abstract \\ The decision in 2005 of the world governing body of cycling, the Union Cycliste \\ Internationale (UCI), to introduce a new competition, the UCI Pro Tour, was a highly \\ significant development in the professional road cycling. Using this development as \\ the case study setting, this paper seeks to illustrate stakeholder theory and network \\ theory at work in a changing environment. Drawing on a series of semi-structured \\ interviews with key stakeholders, complemented by analysis of publicly available \\ information, this study explores how the process of change has affected the \\ professional road cycling network, the interaction between its stakeholders and the \\ balance of power among those stakeholders. While commercialism has a long history \\ in professional road cycling, the paper concludes that the change process has been \\ driven by a wish for commercial deepening within the network and of a desire to \\ challenge some of the well-established relationships and dependencies that have \\ existed therein.
}




\section{Introduction}

In 2005, the world governing body of cycling, the Union Cycliste Internationale (UCI) replaced its World Series of professional road cycling race events with a new competition - the UCI Pro Tour. While season-long competitions had been in place since 1948 (Desbordes, 2008), the Pro Tour was a radical change in that it sought to create a super league in professional road cycling, in which all of the best riders and the best events, and in particular the three major stage races, the Grand Tours, were included. Initially presented as an opportunity to modernise the sport and to develop it as an industry, the organisational structure of professional road cycling, combined with its peculiar economic structure, has resulted in the Pro Tour becoming the focus of a bitter power struggle between stakeholders in professional road cycling. In particular, the dispute between major race organisers (such as the Amaury Sports Organization (ASO), organisers of the Tour de France, cycling's highest profile event) and the UCI has threatened the very existence of the sport.

In this paper, professional road cycling is characterised as a stakeholder network; a series of actors or stakeholders connected by a set of ties. Figure 1 provides a representation of the stakeholders involved in the network and of the main relationships that exist between those stakeholders. For many of the stakeholder relationships indicated, to some extent at least there is influence in both directions 
therein. As appropriate the thickness of the lines has been used to indicate the most central and important relationships.

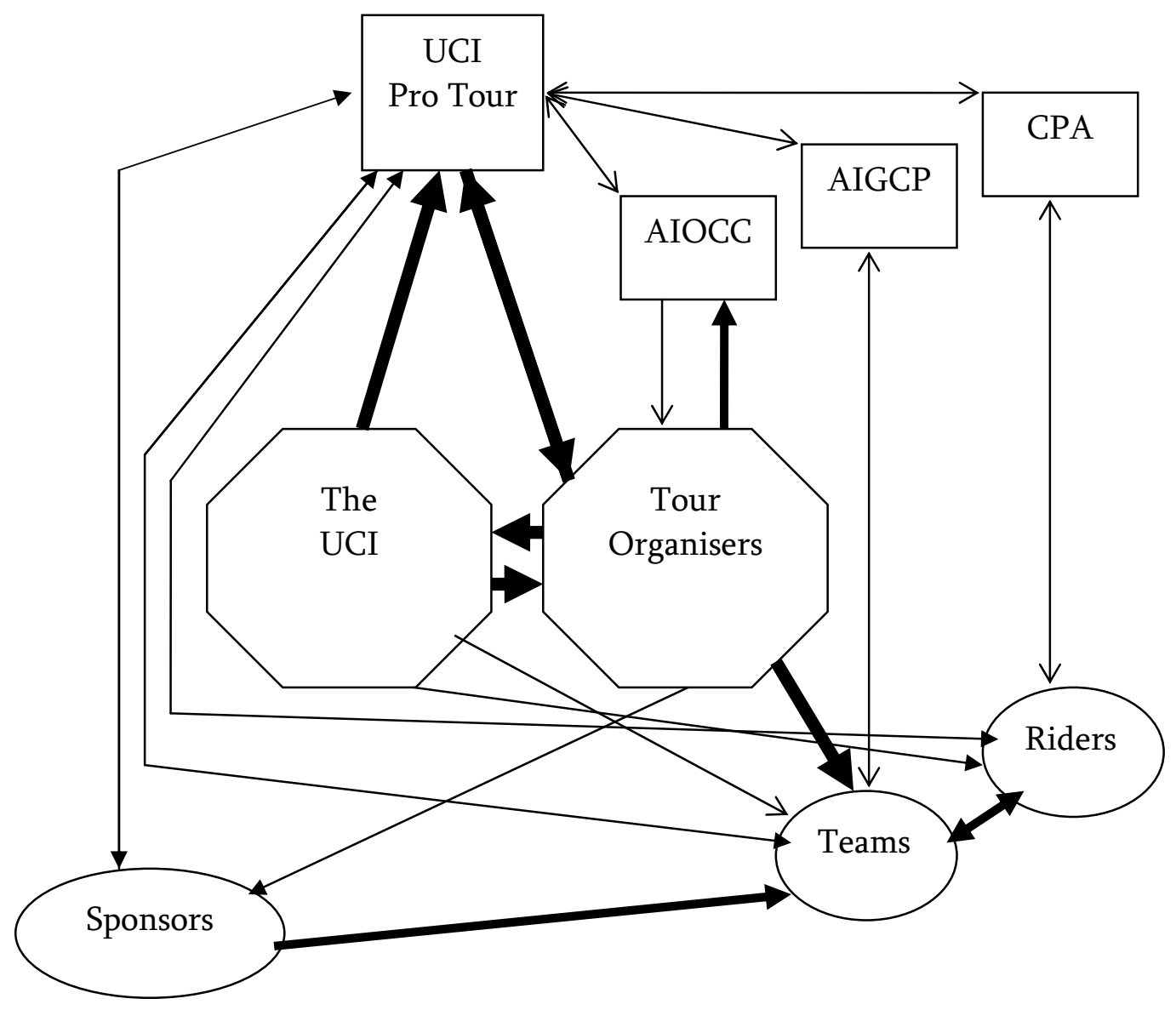

Figure 1. The organisational structure of professional road cycling 


\section{LEGEND}

UCI Pro Tour governed by the UCI Pro Tour Council; it manages the UCI Pro Tour on behalf of the UCI.

AIGCP International Association of Professional Cycling Groups (umbrella organisation for the cycling teams).

CPA Association of Professional Cyclists (umbrella organisation for the riders).

AIOCC International Association of Organizers of Cycling Races (umbrella organisation for the race organisers).

The aim of the paper is to illustrate theory in the context of change within professional road cycling; using that theory to demonstrate the changing configuration of the professional road cycling network and its characteristics. While stakeholder theory is the dominant theoretical perspective used in the paper to illustrate change, its nature, coupled with the structure of professional road cycling, means that a number of closely related theoretical approaches relating to network theory, power and political economy are also drawn on.

The paper is structured as follows: The first section draws on the existing literature to provide a theoretical background for the case study. With this in mind, the next section presents the contextual background to the study, namely the introduction of the UCI Pro Tour. This provides the setting for the case study and leads into the 
section justifying the methodology and methods adopted in this paper. Rather than seek to advance theory based on the feature of this particular case, instead this paper uses the case study and its findings to illustrate theory. This forms the basis of the next section of the paper, followed by the conclusions.

\section{Theoretical Background}

While the origins of stakeholder philosophy can be traced to the early nineteenth century and the early forms of co-operative industrial organisations promoted by entrepreneurs and social reformers like Robert Owen in New Lanark (Clarke, 1998), it was the somewhat more recent publication in 1984 of Edward Freeman's book Strategic Management: A Stakeholder Approach, which integrated stakeholder concepts into a coherent construct and acted as the catalyst for the proliferation of stakeholder-based literature spanning various academic subject areas.

Freeman defined a stakeholder as 'any group or individual who can affect or is affected by the achievement of the organisation's objectives' $(1984,46)$. While the definition is not universally accepted and has been criticised as being so broad that it is meaningless (Sternberg, 1999), it, or some modification thereof, has been utilised by many researchers. Within stakeholder-based research, considerable emphasis has 
been placed on the identification of stakeholders and on determining the types of influence that they exert (Rowley, 1997).

Stakeholder management techniques have been identified as being of value to sport managers in trying to achieve their objectives in sports organisations ranging from global sporting organisations through to community-based clubs (Friedman et al., 2004). A number of authors have used stakeholder theory and stakeholder management to analyse behaviour and objectives in sport-based organisations including major events (Parent, 2008; Parent \& Séguin, 2007), inter-collegiate athletics (Wolfe \& Putler, 2002), public funding for professional sports facilities (Friedman \& Mason, 2004) and franchise relocation (Mason \& Slack, 1997). Several studies of professional football clubs have also explored the relevance of stakeholder theory as a way of explaining behaviour in an industry undergoing dramatic change, most notably change arising from the substantial increases in income and financial rewards available in that sport since the early 1990s (Farquhar et al., 2005; Hamil et al., 1999; Holt, 2007; Morrow, 1999, 2003; Senaux, 2008). While stakeholders in football clubs have probably never had a unitary objective - despite simplistic rhetoric about success (Stewart, 1986) - the business transformation has resulted in the objectives of stakeholders in contemporary clubs becoming more diverse than ever (Morrow, 2003). This point is reinforced by Senaux (2008) who argues that the generic description of utility maximisation masks a serious of complex and often 
incompatible stakeholder goals. Wolfe and Putler (2002) extend this by challenging the implicit assumption within stakeholder theory, that priorities within role-based stakeholder groups, rather than between stakeholder groups, are relatively homogeneous.

Much of the early literature on stakeholder theory was organisation-centric (Friedman \& Miles, 2002); characterised in terms of separate, 'hub and spoke' relationships between an organisation and its stakeholders; understanding how individual stakeholders influence an organisation's operations (Freeman, 1984). Increasingly, it was recognised that an understanding of how organisations respond to those influences and a consideration of the multiple, complex and interdependent interactions that simultaneously exist in stakeholder environments was also required (Borgatti \& Foster, 2003; Friedman \& Miles, 2002; Neville \& Menguc, 2006; Rowley, 1997). In their paper on the organisation of a major swimming event, Parent and Séguin (2007) suggest that stakeholder theory is a good theoretical framework to use when examining multiple perspectives inherent therein.

Of particular interest in this study is understanding how the changing positions of stakeholders within a particular social structure influence their behaviour (Marsden, 1990). Rowley (1997) used social network analysis to describe how organisations are embedded within a relational network of stakeholders, and how the network's nature 
and the organisation's position therein influenced its response to stakeholder demands. He identified two factors that were central in explaining an organisation's degree of resistance to stakeholder demands: network centrality - the position of an actor in a network relative to other actors; and network density - the level of connectedness between actors within the network.

Power is an important concept in the application of stakeholder theory to relationships in a sporting network and in understanding those relationships. While many definitions of power exist, an appropriate starting point is Weber's (1947) definition that actors in a social relationship possess power when they have the ability to exercise their own will, despite resistance. This focus on power as an attribute of an individual stakeholder can be seen as problematic as it does not consider the possibility that power may arise out of the social relationships between stakeholders (Martin, 1971), relationships that are often multi-faceted and inter-dependent (Emerson, 1962). Frooman (1999) suggests that power can also be an attribute of a relationship between the stakeholders, rather than of the stakeholders themselves. The importance of relationships in understanding power within a stakeholder network is also identified by Neville and Menguc (2006), whose theoretical framework on stakeholder interactions and influence - stakeholder multiplicity takes into account three things: that stakeholder groups can both compete against each other and complement each other; that stakeholders can form strategic alliances 
to increase the persuasive power of their claim; and that their potential to influence an organisation is often influenced by their role.

Podolny and Page (1998) characterise an organisational network [in governance terms] as a collection of stakeholders who have repeating and enduring exchange relations with each other but who lack appropriate legitimate organisational authority through which to resolve disputes that arise through their exchange processes. In this type of network it would be expected that power would be more dependent on things like network structure, position and stakeholder relationships within the network (Rowley, 1997; Brass et al., 1998).

Henry and Lee (2002) use football to illustrate the changing nature of governance and models of power. A largely hierarchical structure in which governing bodies exercised power through their positions has been replaced by an interactive webbased system of systemic governance, one dependent on inter-relationships between stakeholders in which different groups exert power in different ways and in different contexts by drawing on alliances with other stakeholders. For example, increased commercialism and an increased focus on finance have strengthened the power of stakeholders including individual leagues, major clubs and broadcasters, and have facilitated the construction of alliances between them. Holt (2007) characterises European football as a stakeholder network, where power is distributed across a 
number of stakeholders, no single one of which will have a monopoly on change. He argues that UEFA, European football's governing body, has attempted to manage this situation by constructing a stakeholder democracy, integrating clubs, leagues and players into the governance system but without giving up genuine decision-making power. To date, he argues, UEFA has been able to do this because of its commercial and sporting control over the lucrative Champions' League.

Of course, power is not a fixed commodity and nor are the structure or relationships in any network. In particular, any change in stakeholder recognition or behaviour may alter the degree of connectedness between stakeholders in the network and/or the exchange processes that exist between them. This shifting balance of power in a sports network was examined by Wolfe et al. (2002), within the working of a sport network in Ireland. Their study illustrated the success of satellite television in achieving a central position of power within the network and of changing the distribution of power within the network through its management of relationships and in particular through its key role as a distribution source for revenues throughout the network. Consistent with the previous examples on football, commercialism in the form of commercial deepening, where media rights become a more significant source of revenue, has played an important part in changing the distribution of power within a particular network. The increased commercialism and focus on finance within sport generally (Schimmel, 2005), is of particular interest when considering 
global sporting organisations and their role within stakeholder networks, given that the traditional focus of these bodies has been on non-financial objectives (Forster \& Pope, 2004).

\section{Contextual Background}

The UCI administers the regulation of all cycling disciplines including mountain biking, track cycling, cyclo-cross, BMX and para-cycling, as well as professional road cycling - the focus of this paper. Founded in 1900 by the national cycling organisations of Belgium, USA, France, Italy and Switzerland, the UCI has not, however, always held governance over all aspects of cycling. Separate amateur and professional cycling federations were developed in 1965, with the largest body, the International Federation of Amateur Cycling, dealing with the Olympic Games. Although the UCI acted as the co-ordinating body for both, they remained separate until 1992 when the two bodies were reunified back into the UCI. Within professional road cycling, the UCI oversees competitive events and its regulatory role includes: licensing racers and races, the provision of referees and adjudicators, and the enforcement of disciplinary rules, most notably for doping.

Professional road cycling has a long history. Its development began with the birth of the Belgian and French 'Classic' races such as the Liège-Bastogne-Liège (first staged as 
a professional event in 1894), Paris-Roubaix (1896) and Paris-Brussels (also 1896). The sport's highest profile event, The Tour de France, a 3-week stage race that takes place in July every year on public roads across France, was first staged in 1903. The Italian equivalent, the Giro d'Italia, first took place in 1909 while the inaugural Vuelta a España was held in 1935. Known as the three Grand Tours, these three-week stage races are widely regarded as the foundation upon which modern day professional cycling is built. Recognised as the ultimate endurance events, the three main tours are celebrated as social and cultural tributes to their host countries and are subjects of intense national pride and prestige (Dauncey \& Hare, 2003). While the basic structure of these stage races is largely unaltered, there have been major changes in the way in which they are run, financed and controlled. For example, the Tour de France was run for competing nations prior to the introduction of the commercial publicity caravan and private sponsorship of individual teams in 1930. However, from the perspective of the sport as a whole, that these and similar races and events continue to be the central components of today's professional road calendar demonstrates the unchanging nature of the sport. In view of this, the establishment in 2005 of the UCI Pro Tour is a highly significant change in the sport.

Professional road cycling is a sport founded on commercialism. The early classic races rapidly captured the interest of the spectating public and business sponsors were quick to see the commercial potential in being involved with stage races. Several 
famous races were founded by newspapers as publicity events to boost their circulation (L'Auto, Tour de France; Gazzetta dello Sport, Giro d'Italia; Informaciones, Vuelta a España), while the Tour de France's publicity caravan was introduced in 1930s as a means of encouraging private sector finance into the sport (Desbordes, 2006).

Professional road cycling is essentially a private sector sport. The Grand Tours are owned and managed by commercial organisations. Most prominent is Amaury Sports Organisation, which arranges the Tour de France, by the far the wealthiest and most important cycling race in the world. Its turnover in 2006 was $€ 145.8 \mathrm{~m}$ (AS0, 2007) of which about $70 \%$ is derived from cycling (Desbordes, 2006). Historically, it has been a very powerful participant within professional cycling through its control of the team invitations to the Tour. Under this structure, teams - and by extension sponsors and riders - were largely beholden to major race organizers like ASO which controlled entry to their events. This dependency was a major problem for teams negotiating with potential sponsors, as clearly they could not provide the sponsors with a guarantee as to the visibility of their brand, thereby introducing uncertainty in terms of a sponsor's expected financial return (Desbordes, 2006). As sponsorship provides almost all of a team's income, this uncertainty had major implications for a team's ability to pay its riders and cover operational costs. 
Race organisers' turnover comes from television rights, sponsorship and advertising, and from public funds (fees paid by local and regional councils to host stages of the race). For example, the City of London paid approximately $€ 4 m$ to host the PreTour and the first two stages of the Tour de France in 2007. Unlike other professional sports, because races take place on public roads, no revenue is derived through gate receipts. Moreover, professional road cycling is an unusual mixture of individual and team sport, with individual cyclists employed by private teams who are funded by sponsors. (For an overview of the economics of professional road cycling, see Desbordes, 2006; 2008; Morrow \& Idle, 2008; Rebeggiani \& Tondani, 2008).

In 2005, the UCI replaced its World Series of professional road cycling race events with a new competition, the UCI Pro Tour. Made up of 27, mainly classic races within the European professional road cycling calendar, the most prestigious events such as the three Grand Tours - were included in the Pro Tour, in addition to some lesser-known races. To take part in Pro Tour events, cycling teams must apply to the UCI for a Pro Tour licence, which is ordinarily valid for 4 years. The Pro Tour is an oligopoly, with the UCI acting as the regulatory agency that owns the monopoly of the licences (Rebeggiani \& Tondani, 2008). Only twenty teams are granted a Pro Tour licence, with each team then being obliged to send riders to compete in all 27 Pro Tour races, although they are allowed to draw on different riders for different events. The main difference from the previous system is that the Pro Tour is a closed 
structure with usually only two 'wildcard' places granted to continental teams with best performances over the season. According to the UCI, the Pro Tour has three main objectives:

- to make cycling more attractive to the public, especially by improving participation levels at key events of the season.

- to increase the interest that cycling generates with investors, by offering teams, organizers, broadcasters and their main partners, guarantees as regards the profit that they will make from their investment.

- to contribute to the development of cycling on all continents.

The UCI Pro Tour ran for the first time in 2005. While the original concept of change was widely supported by various stakeholders involved in cycling (including the major race organisers), its subsequent creation has been controversial with widespread evidence of stakeholder conflict (set out in the following results and discussion section). The UCI and the organisers of the three Grand Tours were unable to reach agreement on the format of 2006 UCI ProTour, such that the status of some of the events within the Tour was unclear. In simple terms, the UCI Pro Tour included events for which the race organisers had not sought Pro Tour licences. Nevertheless, Alejandro Valverde was crowned Pro Tour champion although even his moment of glory was overshadowed when RCS, organisers of the Giro d'Italia (one of 
the organisers which had not sought a Pro Tour licence), refused to allow him to be awarded the Pro Tour jersey at its event. The dispute became more heated in the lead up to the 2007 UCI Pro Tour. Only days before the start of the first event of the competition series, the Paris-Nice race, it seemed certain that the event would not take place at all after race organisers, ASO, refused to allow some of the Pro Tour licensed teams to participate. This refusal was made on the grounds that, as it had made no application to the UCI for its race to be licensed as a Pro Tour event, ASO was at liberty to invite whichever cycling teams it wished to take part in its event. The UCI responded by refusing to provide governing body officials to regulate the event. Unperturbed, ASO claimed it would run the race as a national event, without UCI backing, with referees from the French cycling federation officiating instead. As the remarkable 'tit-for-tat' exchange continued, this decision resulted in the UCI instructing all Pro Tour teams not to participate in ASO events. The cycling teams then issued public statements calling for the organisers and UCI to resolve the dispute for the good of cycling (Morrow \& Idle, 2008). At the eleventh hour a compromise was reached. (More detailed background information is available at www.cyclingweekly.co.uk News Archive). 


\section{Method}

\section{Setting}

The setting for this paper is the network related to professional road cycling. More specifically, within this network the focus of the paper is on the change which resulted in the setting up of the UCI Pro Tour, as set out in the preceding section. This research has focused on the period since 2002 when the first formal noting of major organisational change was made (minutes of the PCC (Professional Cycling Council), No. 7/2002, set out in Official News Bulletin, No. 36, January 2003).

The aim of this paper is to use this case study to illustrate theory at work, in particular stakeholder theory and network theory. Case studies are recognised as being of particular value in providing detailed knowledge of complex events as they develop over time (Parent \& Séguin, 2007). Case study research involves the investigation of a contemporary phenomenon within its real-life context; when the boundaries between phenomenon and context are not clearly evident; and in which multiple sources of evidence are used (Yin, 1984). Case studies are particularly useful in looking at the application of stakeholder and network theories as they provide an opportunity to consider not just the voice and perspective of stakeholders, but also of 
the relevant groups of stakeholders and of the interaction between them (Tellis, 1997).

\section{Data collection}

There were two data collection approaches in this case study: a) gathering data from archival material, and b) semi-structured interviews with key stakeholders.

The first of these approaches involved collection of secondary data obtained mainly through analysis of publicly available information related to the UCI, available either at its headquarters in Aigle, Switzerland or on-line. This information included:

financial statements of the UCI for the years 1999/2000 - 2003/04;

- budgets presented to the UCI annual congress for the years 2002-2006 (inclusive);

legal and constitutional documents, such as the UCI Constitution and its Rules for Good Governance;

records and minutes of its activities and decision making in various committees as set out in its Official News Bulletins. The Official News Bulletins covered the period from January 2003 (No. 36) until April 2006 (No. 45). 
In addition, detailed study was carried out of cycling-specific sources, in particular the UK-based Cycling Weekly magazine, but also internet-based cycling sites such as Cycling News (www.cyclingnews.com). This material was used to better understand the structure of professional road cycling, the role of the various stakeholders, their involvement in the restructuring discussions and processes, and their attitudes to the proposed restructuring.

In a study in 2003, O'Brien and Slack analysed structure and change in the organisational field of English Rugby Union. Their approach involved identifying an $a$ priori coding scheme based on a number of signposts to indicate shifting logics or change in the field, specifically changes in: actors or stakeholders, exchange processes and inter-organisational linkages, legitimised forms of capital, and regulatory structure (O’Brien \& Slack, 2003). In this study, the themes that best illustrated change within the professional road cycling network were drawn from the review of literature, coupled with the analysis of the archival material. This provided three key themes: 1) changes in stakeholder nature, 2) changes in power and 3) changes in stakeholder linkages and coalitions. In addition, an important over-arching theme of commercialism was identified. 
The second source was primary data obtained from a series of semi-structured interviews held with key stakeholders in professional road cycling. An important challenge in using interview data is to limit bias (Eisenhardt \& Graebner, 2007). To mitigate bias, interviewee selection reflected their anticipated knowledge of professional road cycling and the setting up of the Pro Tour, and their markedly different roles within cycling, which it was hoped would illuminate diverse perspectives on the sport and the changes therein. Stakeholders from the network interviewed included representatives from the governing body, from race organisers, from teams, from umbrella organisations and with relevant individuals not directly involved in professional road cycling, such as journalists. Within the governing body, interviews were held with representatives from different levels within the organisation. To that end, interviews were conducted with representatives of the UCI (the President, the Pro Tour Manager, the Press Officer), ASO (the Chief Executive of the Tour de France), RCS (the Director of Organisation of the Giro d'Italia), the Administrative Director of a UCI Pro Tour Cycling team and the Professional Cyclists' Association. These interviews lasted for between 60 and 90 minutes each on average. In addition, two shorter interviews were held with editorial staff of two UKbased cycling magazines. Interviews were held between May 2006 and January 2007 with several of the interviews being conducted in French or Italian by one of the authors. While the number of interviews is relatively small, the main interviewees, all of whom were based in continental Europe, are representative of the key 
stakeholders in the professional road cycling network. All interviewees provided their consent for their views to be reported in academic publications.

Questions focused on the themes identified as illustrating change within professional road cycling and sought to identify the values, attitudes, behaviour and professional interests of those involved. The interviews were translated (as required) and transcribed and organised around these themes. Where possible the interview material was compared to the secondary information published by the UCI. The discussion section of the paper which follows is structured around those same themes.

\section{Results and discussion}

Changes in Stakeholder Nature

As set out earlier in the paper, the structure of professional road cycling directly involves a number of separate stakeholders: race organisers, teams, riders, sponsors and governing bodies. Prior to the inception of the Pro Tour, there was widespread acceptance from the various stakeholders, including the organisers of the Grand Tours, that there was a need for structural change to create a proper hierarchy of events. Road cycling was seen as fragmented which restricted its opportunities to develop as a sport and to prosper financially. To increase its public visibility and 
attractiveness to broadcasters in particular, there was a recognised need to improve the coherence and presentation of the product. To facilitate this commercial deepening, it was acknowledged that it was essential to attract the top riders to the big races:

... we had started to pile up the competitions and there wasn't much point to it any more. It was time to start again and to make some kind of reform that would make high level cycling more visible to the public and the media. Why? To conquer television, which is the base of everything. If you are shown on television, you'll get sponsored (interview with Jean Marie Le Blanc, former CEO of the Tour de France, May 2006)

... the idea of increasing the quality of cycling is right and current. Otherwise we risk being left behind and as a result we'll lose market share, opportunities everything (interview with Mauro Vegni, Director of Organisation, RCS Sport, September 2006)

Historically, the UCI had acted as a traditional regulatory body within professional road cycling: licensing racers and races, the provision of referees and adjudicators, and the enforcement of disciplinary rules, most notably for doping. In the wider sporting environment, there have been changes in the political economy of Global Sporting 
Organisations (GSOs). One example of this has been moves by some GSOs to lessen their financial dependence on national associations and/or member clubs, a move often predicated on their control of a hallmark event (Forster \& Pope, 2003). In contrast, as the UCI does not control major events in the professional road cycling calendar (for example, the Tour de France is controlled by the private company, ASO); it continues to be financially dependent on national cycling associations. Notwithstanding the UCI's legitimacy as a governing body, the fragmented structure and the multiple stakeholder groups found in professional road cycling, mean that its influence has been relatively limited.

Through the Pro Tour, the UCI has sought to position itself more centrally in the network (Rowley, 1999); seeking to change its nature and position as part of the process of trying to drive change in professional road cycling. The UCI has sought to justify its changed role in terms of being for the good of the sport, i.e. the change process and its position therein enables the governing body to focus on improving professional road cycling's position and prominence in the global sport market place; facilitating its sports development role and enabling the sport and its stakeholders to prosper financially.

The rationale basically is that sport is sport is sport. ... We can never forget that. But by the same token at the top level, sport is also to some extent ... business ... 
commerce. ... we are in competition with other sports; we are in competition for television ... the more the sport gets into the public arena, the better for the possibilities of development of the sport. ...

But we don't have a commercial interest in terms of making money out of this. Our focus is purely on the sport, the development of the sport and we make the decisions - objective decisions - related to the development of the sport. All the different stakeholders have to accept that (interview with Pat McQuaid, UCI President, June 2006).

But its motivation to change and for change may also be characterised in more instrumental terms and contrary to the views set out above. In particular, it has been argued that the UCI viewed the Pro Tour as the route to positioning itself as a more direct financial beneficiary from the revised structure of road cycling, indirectly assisting it to fulfill its aspirations for cycling as a whole.

It's there [the Pro Tour] that the UCI has transformed its vocation - from federation which should protect and defend, provide rules and regulations, into a commercial machine (interview with Mauro Vegni, RCS Sport, September 2006).

Certainly the UCI's strategy for change has emphasised commercial considerations: first, collective benefits arising out of the philosophy of excellence that underpinned 
the Pro Tour (interview with Pat McQuaid, UCI President, June 2006), and second, individual benefits, particularly financial, arising from the Pro Tour. For example, the financial certainty arising out of the closed-structure of the Pro Tour and the existence of four-year licences was clearly attractive to teams, sponsors and riders and highlights the importance of commercialism.

All we want to do with the Pro Tour is create new opportunities to improve the situation of the licence holders (interview with Alain Rumpf, UCI Pro Tour Manager, June 2006).

From the riders' point of view, the Pro Tour has brought quite a few things ... more financial status and more security because if the team sponsors are sure to have a contract for 3 or 4 years [then] it is easier for the riders to negotiate contracts for 3 or 4 years. [And] as there is more money, the contracts are of more financial value (interview with Daniel Malbranque, Secretary General, CPA (Professional Cyclists’ Association), November 2006)

For the teams and sponsors, it is a great thing because it means that for the period ...[that you have a licence] you have no concerns about whether you will be participating in the Tour de France ... it's the same for the sponsors ... it is certain 
that their team jersey will be in the Tour so they are happy (interview with Franck Trajber, Administrative and Financial Director, Cofidis, December 2006).

We're making decisions or asking for support or advice to make decisions which are to the benefit of the stakeholders, not to our benefit but to the benefit of the stakeholders and all the sponsors and the teams and the riders. At the end of the day if this thing grows and grows and cycling gets more coverage from television and therefore more money coming into it, it is all the stakeholders who benefit from that additional money (interview with Pat McQuaid, UCI President, June 2006).

The importance of commercialism in explaining behaviour and positioning within a network has also been observed in other sports, notably European club football where structural change in the UEFA Champions' League has been driven by financial considerations, in particular the distribution of media income and the desire of the major European clubs to guarantee their participation in the competition's lucrative later stages (Holt, 2002). More specifically, in their study of sports networks in Irish sport, Wolfe et al. (2002) demonstrated the success of satellite television in taking a more central position in the network as a consequence of its role as a distributor of revenue within the network. 
One issue that is highlighted in this type of exchange is the homogeneity of stakeholder groups. For example, while organisers of smaller races like the DauphinéLibéré were in favour of the proposed UCI Pro Tour as it dramatically improved the quality of riders and teams taking part (interview with Daniel Malbranque, Secretary General, CPA, November 2006), as will be seen in the following section, resistance to change came from the organisers of major events and races who saw the Pro Tour as weakening their control over participation in their events. This difference of opinion emphasises one criticism of stakeholder theory; its implicit assumption that priorities within role-based stakeholder groups are relatively homogeneous (Wolfe \& Putler, 2002).

A related issue is stakeholder representation. Clearly, all race organisers do not share the same objectives, yet the management and governance structure within which professional road cycling operates (both pre- and post- Pro Tour) involves umbrella groups set up to represent all race organisers (AIOCC), all teams (AIGCP) and all riders (CPA) (see Figure 1). The governance challenges are exacerbated by the fact that these umbrella groups draw their representation directly from the race organisers, teams and riders, with the result that particular individuals can be placed in situations where their organisational position (e.g. as a race organiser) is in conflict with the position of the umbrella organisation. The following extract from the 
minutes of the meeting of the PCC held in Bardolino del Garda in October 2004 highlights precisely the problem of stakeholder representation:

\section{UCI Pro Tour: Project Progress Report}

Jean Marie Le Blanc and Carmine Castellano made no comment at this meeting on Grand Tours. They would be taking part on behalf of the AIOCC [umbrella organisation representing all race organisers] and not on behalf of ASO [organiser of The Tour de France and Le Blanc's employer] and RCS [organiser of the Giro d'Italia and Castellano's employer] respectively.

\section{Changes in power}

One stated objective behind the Pro Tour was to increase the financial rewards available to all those within the sport. A key issue here is the extent to which stakeholders consider this at the institutional level - for the good of the sport - or from a narrower, but rational, stakeholder self-interest, focusing more on their power and control over the generation and distribution of revenue and their human capital. To some within different stakeholder groups (teams, sponsors and riders), part of the appeal of the new structure was that it challenged the power of the organisers of the major races, ASO (organisers of the Tour de France) and to a lesser extent RCS (organisers of the Giro d'Italia) and Unipublic (organisers of the Vuelta), whose 
influence arose out of their historical control of starting places in their events. Under the previous structure, securing a place in the Tour de France, was often crucial to the financial viability of teams, sponsors and riders. In this context, however, notwithstanding the collective benefits that had encouraged the early stakeholder dialogue and appetite for change, it is perhaps unsurprising that ultimately the major race organisers interpreted the Pro Tour as a challenge to their autonomy and to their ability to manage their businesses:

Over the past two years ... [the UCI] has made a huge mistake - thinking that it had power over everything and everyone and that it could even manage things that historically were the rights of other individual organisations (Mauro Vegni, RCS Sport, September 2006).

And on the other hand we didn't want to lose - not necessarily money - but our savoir-faire and experience. We have been owners of the brand of the Tour de France for 100 years. I don't see why tomorrow we shouldn't still be doing our jobs (Jean Marie Le Blanc, Tour de France, May 2006).

Equally unsurprising was their decision to try to use their power to block change and to preserve their positions. One example of this was ASO's refusal to allow all of the UCI Pro Tour licensed teams to take part in the 2007 Tour de France by banning the 
Unibet team from its events, including the Tour de France (Cycling News, 2007) ${ }^{1}$. More fundamentally, the decision of ASO, RCS and Unipublic to withdraw their races from the 2008 Pro Tour is perhaps the ultimate demonstration of power (Whittle, 2007); a reminder to the UCI, teams, riders and sponsors of their control over the sport's most financially lucrative events. More generally, where power and authority are threatened as a result of potential change, resistance is predictable even where such change could be beneficial to the sport as a whole (Patti, 1974).

A central aspect of the dispute between race organisers and the UCI is one common in other areas of sports business - the putative conflicts between sporting, social and financial objectives. One example of this is the UEFA Champions' League, one of the most lucrative financial competitions in club sport, but also a competition in which being a champion on the field of play in a domestic league is no longer sufficient (in the case of countries from smaller media market places), or necessary (in the case of countries with larger media market places) and in which the distribution of financial rewards is only in part a function of sporting success (Morrow, 2003). This aspect is of particular significance in professional road cycling given that events like the Tour and the Giro have always had a commercial dimension to them, and have always been organised by private sector businesses. In this context, the depiction by

\footnotetext{
${ }^{1}$ The following year, ASO refused to allow another Pro Tour licensed team, Astana, to take part in the 2008 Tour de France, citing previous drug-related scandals in the team. This decision was taken despite the fact that Astana is the team for which the winner of the 2007 Tour de France, Alberto Contador.
} 
representatives of ASO and RCS of the UCI as being financially motivated and of losing sight of its legitimate role are worthy of note:

One of the aspects of the break-up was ... the fact that the UCI has developed a more economic role rather than political or sports-focused (interview with Mauro Vegni, RCS Sport, September 2006)

This view of the behaviour of the UCI is consistent with what Forster and Pope (2003) describe as an ends-means inversion by GSOs, the hypothesis being that over time, governing bodies move away from narrow sporting objectives for which they have legitimacy, instead focusing on more economically-oriented organisational ends which allow them to assert their control over the sport. As discussed previously, this process has been more difficult for the UCI, as it does not control a hallmark event. While the UCI Pro Tour offers some opportunity for the UCI to prioritise its financial objectives, more importantly, it provides a mechanism for it to assert its control over the business of professional road cycling (and over the major race organisers), rather than acting simply as the regulator of sporting elements of their professional road races.

In contrast, the major race organisers are keen to emphasise two things, first, that their role in professional cycling and in the network has not changed and second, that 
their role is, and always has been, about something broader than finance or even sport, emphasising aspects of their races' social and cultural capital.

The Tour de France belongs to every French person, to every region. ... The Interior Minister - and I understand him - considers that the Tour de France is part of French national heritage; something important for the image of France (interview with Jean Marie Le Blanc, Tour de France, May 2006).

... in Italy, we represent cycling so we also have some political responsibility. If we were simply a straightforward commercial organisation, we would organise the Giro and maybe a few other events that brought profits in, but since we also have this political duty [to represent and promote one of Italy's national sports], we also organise a series of events where ...very often we lose money. We take money from the Giro funds to subsidise other areas of activity (Interview with Mauro Vegni, RCS Sport, September 2006).

Arguably, the major race organisers are seeking to defend their position within the network by invoking wider social considerations; seeking to position themselves as something more than commercially-focused business people. A similar tactic has been used by UEFA, European football's governing body, in its defence of its Champions' League, where it has emphasised the solidarity payments made to support financially 
weaker clubs and member associations (Morrow, 2003). One other consideration is human capital, or perhaps more accurately the role of personalities. Power can be at the level of individuals or organisations, or through positions (Slack \& Parent, 2006) and previous studies of business behaviour and governance in sports like football have stressed the importance of personality (Morrow, 2003). While the development of the Pro Tour has emphasised issues as diverse as sports development, competitive quality, business structure and governance, fundamentally its developments and the subsequent conflict have also been about the power and influence of key individuals within those stakeholders.

There has been so much that has happened between Verbruggen [previous president of the UCI] and Patrice Clerc [Head of ASO] and now Pat McQuaid [current President of the UCI] and Patrice Clerc. ... It has become a battle between two men, two individuals rather than the organizations they represent (interview with Franck Trajber, Cofidis, December 2006).

\section{Stakeholder coalitions}

Given the initial desire for change expressed by stakeholders within the network, ostensibly the emphasis on stakeholder dialogue as the process through which to achieve change was entirely rational. This is consistent with Henry and Lee's (2004) 
views on systemic governance, where they stress that major policy change is only possible if there is negotiation and compromise between stakeholders in the network. At the same time, the potential for stakeholders to build coalitions within a network, strengthening relationships between sources of dependence, as a way of challenging long-standing, powerful interests has also been commented on in the literature (Benson, 1975; Podolny \& Page, 1998). In the case of professional road cycling, the inception of the Pro Tour has acted as a catalyst for the teams, the sponsors and, to a lesser extent, the riders, to begin to coalesce with a view to challenging the power of race organisers like ASO. While the previous structure resulted in teams, and by extension sponsors and riders, having a dependency relationship with the major race organisers which controlled entry to their events, the Pro Tour structure is based on a transparent and predictable system of participation and financial reward; characteristics that were appealing to teams, sponsors and riders.

Both Frooman (1999) and Neville and Menguc (2006) stress the opportunities for stakeholder alliances to secure influence, in ways that individual stakeholders can not. The UCI's approach of focusing on stakeholder dialogue to facilitate change has encouraged some stakeholders to work together to try to reduce uncertainty and to influence change, even when faced by resistance from powerful stakeholders within the network. The initial willingness of the teams and the sponsors to side with the UCI and to challenge the established power and authority of the race organisers has 
clearly altered the nature of the network and the interconnectedness between its actors. One example is the relationship between the teams, to whom Pro Tour licenses are awarded, and team sponsors, which fund the teams. While the teams have traditionally played a part in the governance of road cycling through the umbrella organisation, AIGCP, the sponsors were previously largely disengaged from governance and decision-making. However, their enthusiasm for the marketing and television possibilities arising from the Pro Tour resulted in them agreeing to assume a stronger and more direct role within the ProTour (First Edition Cycling News, 2005). Moreover, the perception of the teams and sponsors beginning to organise themselves and assert their influence over the sport in other ways has been noted by other stakeholders:

[the teams will] fight to hang on to [their Pro Tour licences]. ... they are in the middle of setting themselves up [like] the G14 in football. We can see the idea starting to form within the teams to build a kind of force against us [the race organisers]. And perhaps against the UCI as well, I don't know (interview with Jean Marie Le Blanc, Tour de France, May 2006).

Interestingly, at the same time some stakeholders have argued that coalitions of mutual interest have also emerged on the other side of the dispute, emphasising again the contested nature of the change process: 
I am convinced that the Pro Tour is already dead. The big tours are no longer alone now. They have ... the 4 most important federations ... the Spanish, French, Italian and Belgian [on side].... This ... should make the UCI stop, sit down and take a minute to think about things. To go to war with the 3 main tours means they're already taking on a big war. To do so with the 3 or 4 most important national federations is a huge risk (Mauro Vegni, RCS Sport, September 2006).

\section{Conclusion}

Commercialism has been an important factor within the professional road cycling network virtually since its inception. Indeed, within the race organisers' stakeholder group, the central role and powerful position of organisers like ASO have arisen largely through their ability to control access to their commercial events and as a result of the subsequent distribution of finance. But what this study has shown is that while commercialism continues to be an important factor in the workings of the professional road cycling network, change within the network has been driven by stakeholders other than the major stage race organisers, seeking to alter their position within the network by adopting a more commercially-focused approach. In keeping with the changing political economy of global sporting organisations more generally, 
this is particularly the case for the governing body, the UCI, which through its advocacy of the Pro Tour as a form of commercial deepening, has sought both to strengthen its position within the network and to develop its links with other stakeholders.

It now appears that the UCI Pro Tour as originally conceptualised has failed: no ASOmanaged events have been included in 2007/08, meaning that the sport's highest profile events like the Tour de France will be run separately as part of the European calendar. However, the Pro Tour will continue in 2007/08 with new events being held in countries like Australia, China and Russia (see Postscript). One interpretation of this state of affairs is that the battle has been won by the powerful race organisers and hence lost by the UCI, and by the other stakeholders in the network (Whittle, 2007). But in truth, the reality is more complex.

Irrespective of the precise format of the UCI Pro Tour going forward, the case study has demonstrated the application of stakeholder theory and network theory in practice. The change process as encouraged by the UCI has involved widespread stakeholder dialogue within the network. But, while dialogue is a pre-requisite to major policy change within the network, ultimately the acceptance of change within a network is dependent on more complex factors like the nature of the individual stakeholders, the positioning of stakeholders within that network, the connections 
between them and, importantly, the distribution of power within the network. The readiness of the teams and the sponsors to form an alliance with the UCI has changed the nature of the network and the relationships therein, and as a result has challenged the position of the major race organisers within the network. To some extent at least, power has been dispersed among different stakeholders within professional road cycling, such that the substance - if not necessarily yet the form - of the network configuration has been altered. In particular, the wider emphasis on commercialism has lessened the dependency of stakeholders on race organisers like ASO.

Looking ahead, the dispute surrounding the Pro Tour and the entrenched positions taken by individuals and organisations has, to an extent, been overtaken by events. In particular, the continuing drugs scandals, most notably in the 2007 Tour de France, are threatening both cycling's sporting credibility and its commercial potential, with a number of sponsors and media companies choosing to end their relationships with the sport. Paradoxically, these scandals and their financial consequences may end up being the channel which forces all of the major stakeholders to work together for change and to restore the sport's credibility. Already some teams, riders and sponsors have taken a lead in this; most notably team Slipstream's zero tolerance policy on drugs among its riders and the public anti-drugs pronouncements of younger riders like Britain's Bradley Wiggins. The UCI believe that its attempting to globalize the Pro Tour will not only help develop the sport of road cycling but may also have a role 
to play in dealing with the issue of drugs, challenging the powerful position of a small number of race organizers in a small number of countries. For race organizers like ASO, it could be argued that from one perspective nothing has changed, but in fact everything has changed. ASO events like the Tour de France will be under greater scrutiny than ever before and it is clear that it can not afford to stage another race overshadowed by drugs-related controversy.

Returning to change and the Pro Tour, the race organisers find themselves at a critical juncture: if they are to thrive as business organizations and play a role in developing their sport, they need to work with cycling's other stakeholders to earn their central role in the network - rather than assuming it is their's by historical right.

\section{Postscript}

The rift between race organizers ASO and the UCI continues. In September 2007, in a renewed attempt to exert its power as a governing body, the UCI excluded all ASO events - including the Tour de France - from the Pro Tour calendar. In place of the traditional 'Classic' races, such as the Paris-Nice, Flèche Wallone and the Tour de France, the UCI were keen to bring a completely new and more global aspect to the Pro Tour. 2008 will introduce the Australian 'Tour Down Under' as the first Pro Tour event to be staged outside Europe. China and Russia are two of the 'new' cycling 
countries which are reportedly pushing for the opportunity to host major cycling races and are reportedly prepared to cover the costs of making them lavish events. The attempted internationalization of professional cycling may have come at a timely moment for the UCI. In spite of on-going discussions to resolve the long-running dispute between the two organisations, ASO announced in June 2008 that the 2008 Tour de France would not run under the jurisdiction of the UCI. Instead, the French Cycling Federation will oversee the event and anti-doping controls will be overseen by the French Anti-Doping Agency, the AFLD.

\section{References}

AS0 (2007). Amaury Sport Organisation Assemblée Générale Ordinaire du 29 Juin 2007. Rapport de gestion du conseil d'administration.

Benson, J.K. (1975). The interorganizational network as a political economy. Administrative Science Quarterly, 20, 229-249.

Borgatti, S. \& Foster, P. (2003). The network paradigm in organizational research: A review and typology. Journal of Management, 29(6), 991-1013.

Brass, D.J., Butterfield, K.D. \& Skaggs, B.C. (1998). Relationships and unethical behaviour: A social network perspective. Academy of Management Journal, 23(1), 1431. 
Clarke, T. (1998). The stakeholder corporation: A business philosophy for the information age. Long Range Planning, 31(2), 182-194.

Cycling News (2007). Unibet to pursue damages after ASO denies Flèche Wallonne start. 25 April. http://www.cyclingnews.com/news.php?id=news/2007/apr07/apr25news2 Dauncey, H. \& Hare, G. (2003). The Tour de France, 1903-2003: A century of sporting structures, meanings, and values. London: Frank Cass.

Desbordes, M., (2006). The economics of cycling. In W.Andreff and S.Szymanski (Eds), Handbook on the economics of sport (pp. 398-410). Cheltenham: Edward Elgar. Desbordes, M. (2008). The future of the Tour de Franc: From an independent style of organization to 'A Formula One model'? In D.Arthur and S.Chadwick (Eds), International cases in the business of sport (pp. 358-371). Oxford: ButterworthHeinemann.

Eisenhardt, K.M. \& Graebner, M.E. (2007). Theory building from cases: Opportunities and challenges. Academy of Management Journal, 50(1), 25-32.

Emerson, R.E. (1962). Power-dependence relations. American Sociological Review, 27, 31-41.

Farquhar, S., Machold, S. \& Ahmed, P.K. (2005). Governance and football: an examination of the relevance of corporate governance regulations for the sports sector. International Journal of Business Governance and Ethics, 1(4), 329-349. First Edition Cycling News (2005). UCI: ProTeam sponsors support ProTour. 13 December. http://www.bike-zone.com/news.php?id=news/2005/dec05/dec13news . 
Forster, J. \& Ll. Pope, N.K. (2004). The political economy of global sporting organizations. London: Routledge.

Freeman. R.E. (1984). Strategic management: A stakeholder approach. Boston: Pitman.

Friedman, M.T. \& Mason, D.S. (2004). A stakeholder approach to understanding economic development decision making: Public subsidies for professional sport facilities. Economic Development Quarterly, 18(3), 236-254.

Friedman, A.L. \& Miles, S. (2002). Developing stakeholder theory. Journal of Management Studies, 39, 1-21.

Friedman, M.T., Parent, M.M. \& Mason, D.S. (2004). Building a framework for issues management in sport through stakeholder theory. European Sport Management Quarterly, 4, 170-190.

Frooman, J. (1999). Stakeholder influence strategies. Academy of Management Review, 24(2), 191-205.

Hamil, S., Michie, J. \& Oughton, C. (Eds) (1999). A game of two halves? The business of football. Edinburgh: Mainstream.

Henry, I. \& Lee, P.C. (2004). Governance and ethics in sport. In J.Beech and S.Chadwick (Eds), The business of sport management (pp. 25-42). Harlow: Pearson Education.

Holt, M. (2007). The ownership and control of elite club competition in European football. Soccer and Society, 8(1), 50-67. 
Marsden. P.V. (1990). Network data and measurement. Annual Review of Sociology, $16,435-463$.

Martin, R. (1971). The concept of power: A critical defense. British Journal of Sociology, 22, 240-256.

Mason, D.S. \& Slack, T. (1997). Appropriate opportunism or bad business practice? Stakeholder theory, ethics and the franchise relocation issue. Marquette Sports Law Journal, 7, 399-426.

Morrow, S. (1999). The new business of football. Accountability and finance in football. Basingstoke: Macmillan.

Morrow, S. (2003). The people's game? Football, finance and society. Basingstoke: Palgrave.

Morrow, S. \& Idle, C. (2008). The challenges of modernising a professional sport: a case study of professional road cycling. In D.Arthur and S.Chadwick (Eds), International cases in the business of sport (pp. 45-59). Oxford: ButterworthHeinemann.

Neville, B. \& Menguc, B. (2006). Stakeholder multiplicity: Towards an understanding of interactions between stakeholders. Journal of Business Ethics, 66(4), 377-391. O’Brien, D. \& Slack, T. (2003). An analysis of change in an organizational field: The professionalization of English Rugby Union. Journal of Sport Management, 17(4), 417-448. 
Parent, M.M. (2008). Evolution and issue patterns for major-sport-event organizing committees and their stakeholders. Journal of Sport Management, 22(2), 135-164. Parent, M.M. \& Séguin, B. (2007). Factors that led to the drowning of a world championship organizing committee: A Stakeholder Approach. European Sport Management Quarterly, 7(2), 187-212.

Patti, R.J. (1974). Organizational resistance and change: The view from below. Social Service Review, 48, 367-383.

Podolny, J.M. \& Page, K.L. (1998). Network forms of organization. Annual Review of Sociology, 24, 57-76.

Rebeggiani, L. \& Tondani, D. (2008). Organizational forms in professional cycling An examination of the efficiency of the UCI Pro Tour. International Journal of Sport Finance, 3(1), 19-41.

Rowley, T.J. (1997). Moving beyond dyadic ties: a network theory of stakeholder influences. Academy of Management Review, 22(4), 887-910.

Schimmel, K.S. (2005). Sport and political economy: An introduction. In J. Nauright and K.S. Schimmel (Eds), The political economy of sport (pp. 1-15). Basingstoke: Palgrave-Macmillan.

Senaux, B. (2008). A stakeholder approach to football club governance. International Journal of Sport Management and Marketing, 4(1/2), 4-17.

Slack, T. \& Parent, M. (2006). Understanding sport organisations: The application of organisation theory (2nd ed.), Champaign, Ilinois: Human Kinetics. 
Sternberg, E. (1999). The stakeholder concept: A mistaken doctrine. Henley-onThames: NTC Publications Ltd.

Stewart, G. (1986). The retain and transfer system: An alternative perspective. Managerial Finance, 12(1), 25-29.

Tellis, W. (1997). Application of a case study methodology. The qualitative report, 3(3) available at http://www.nova.edu/ssss/QR/QR3-3/tellis2.html .

Weber, M. (1947). The theory of social and economic organization. New York: Oxford University Press.

Whittle, J. (2007). A humiliating shambles. Cycling Weekly, Thursday 15 November, 20-21.

Wolfe, R., Meenaghan, T. \& O'Sullivan, P. (2002). The sports network: insights into the shifting balance of power. Journal of Business Research, 55, 611-622.

Wolfe, R.A. \& Putler, D.S (2002). How tight are the ties that bind stakeholder groups? Organization Science, 13(1), 64-80.

Yin, R. (1984). Case study research. Beverley Hills, CA: Sage Publications 